\title{
Effects of aspect ratio on heat transfer and pressure drop in stationary and rotating two-pass rectangular channels with smooth wall
}

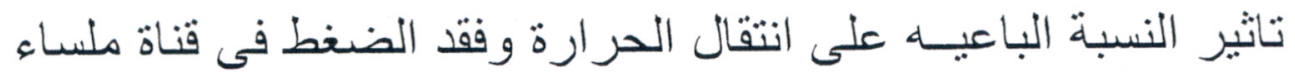 \\ مستطيلة المقطع ذات مسارين في الحالة الساكنة و الدوارة \\ Sabry .M. Ragab ${ }^{(1)}$, Ahmed.A.sultan ${ }^{(2)}$, L.H.Rabee ${ }^{(2)}$ and Moh.EL-Naggar ${ }^{(2)}$. \\ (1) Mech. power engng. email engsabry24@gmail.com \\ (2) prof. of Mech. power engng. Mansoura University. email: AAsultan@mans.edu.eg
}

تم عمل در البحثة:- حسابية على سريان مضطرب ثلاثي الأبعاد وانتقال الحرارة في قناة مستقرة و دوارة ذات شكل مسنطبل

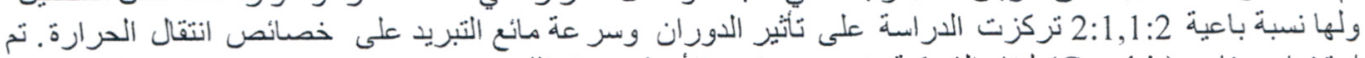

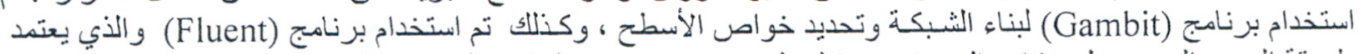

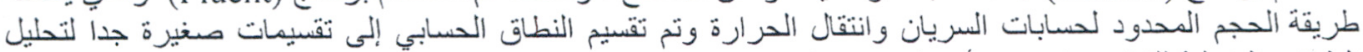

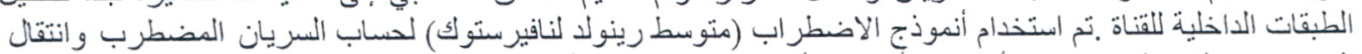

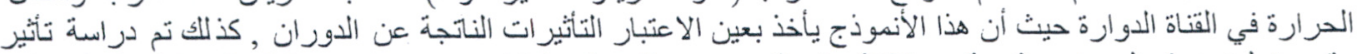

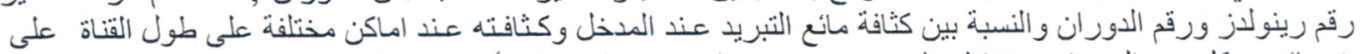

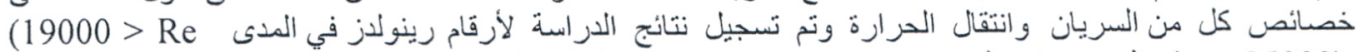

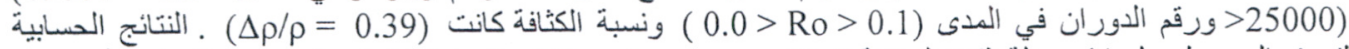

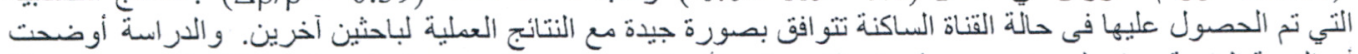

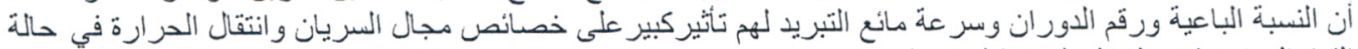

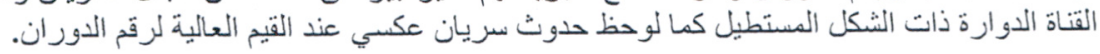

\begin{abstract}
A computational study is performed on three-dimensional turbulent flow and heat transfer in a rotating and non-rotating two-pass smooth rectangular channel with aspect ratio (AR) of $2: 1$ and $1: 2$. The focus of this study is to investigate the effect of rotation, mean velocity of coolant fluid and the aspect ratio on the flow and heat transfer characteristics. A Reynolds-averaged Navier Stokes (RANS) turbulence model was employed to solve the NS-equations. Computations were performed with Reynolds number (Re) ranging from 19,000 to 25,000, rotation number (Ro) from 0 to 0.1 , inlet coolant-to-wall density ratio $(\Delta \rho / \rho)$ was 0.39 . The finite volume code, FLUENT ANSYS 6.3 was used to predict the flow and heat transfer. Computational domain was meshed with fine grids to resolve the near wall viscous layer using GAMBIT grid generator.

Theoretical results obtained for stationary channels are in good agreement with experimental results of other investigators. Also, it is indicated that the aspect ratio, rotation number and fluid velocity has a great effect on the characteristics of flow, heat transfer and pressure drop in case of rotating two-pass rectangular channels. Moreover it is seen that there is a reversible fluid flow at higher rotation number.
\end{abstract}




\section{Nomenclature}

\begin{tabular}{|c|c|c|c|}
\hline$A R$ & Aspect ratio, $W: H$ & $P r$ & Prandtl number. \\
\hline$B o_{x}$ & Rotational Buoyancy. & $Q$ & Heat transfer rate at wall, (Watt). \\
\hline$C p$ & Specific heat at constant pressure, & $\operatorname{Re}$ & Reynolds number. $\left(\rho V D_{h} / \mu\right)$. \\
\hline & $(\mathrm{kj} / \mathrm{kg} \cdot \mathrm{k})$ & Ro & Rotation number, $\left(\Omega D_{h} / V\right)$. \\
\hline$D_{h}$ & Hydraulic diameter, $(m)$ & $R x$ & local radius, $(m)$. \\
\hline$f$ & Friction factor. & $\mathrm{S}$ & Distance in Streamwise direction, \\
\hline$f_{0}$ & Fully developed friction factor in non- & & $(m)$. \\
\hline$h$ & $\begin{array}{l}\text { rotating smooth tube. } \\
\text { Heat transfer coefficient, }\left(\mathrm{W} / \mathrm{m}^{2}, \mathrm{k}\right) \text {. }\end{array}$ & $\begin{array}{l}T P F \\
T_{w}\end{array}$ & $\begin{array}{l}\text { Thermal Performance Factor. } \\
\text { Wall temperature }(K)\end{array}$ \\
\hline$H$ & Channel height, $(m)$. & $V$ & Velocity in streamwise \\
\hline K & Thermal conductivity of coolant, & & direction, $(\mathrm{m} / \mathrm{s})$ \\
\hline & $(W m$ & $W$ & Channel width, $(m)$. \\
\hline k & Turbulence kinetic energy. & $X$ & Distance in streamwise direction, \\
\hline L & Heated section length, $(m)$. & & $(\mathrm{m})$ \\
\hline$\dot{\mathrm{m}}$ & Mass flow rate, $(\mathrm{kg} / \mathrm{s})$ & $X / D_{h}$ & Streamwise dimensionless distance, \\
\hline$N$ & Rotational speed, (rpm). & & $\left(x / D_{h}\right)$ \\
\hline$N u$ & Mean Nusselt number, $\left(h D_{h} / k\right)$. & \multicolumn{2}{|c|}{ Greek letters } \\
\hline$N u_{o}$ & $\begin{array}{l}\text { Nusselt number for fully-developed } \\
\text { turbulent flow in smooth }\end{array}$ & $\varepsilon$ & Rate of dissipation of the turbulence. \\
\hline$N u_{x}$ & Streamwise Nusselt number & $\begin{array}{l}\mu \\
v\end{array}$ & $\begin{array}{l}\text { Dynamic viscosity of coolant, } \\
\text { Kinematics viscosity, }\left(\mathrm{m}^{2} / \mathrm{s}\right) \text {. }\end{array}$ \\
\hline$P$ & Pitch of ribs, $(m)$. & $\rho$ & Density of coolant, $\left(\mathrm{kg} / \mathrm{m}^{3}\right)$. \\
\hline P/e & The rib pitch-to-height ratio, $(\mathrm{m})$. & $(\rho \Delta / \rho)$ & Coolant-to-wall density ratio. \\
\hline$P_{i}$ & Pressure at the inlet section, $(\mathrm{Pa})$. & $\Omega$ & Angular velocity, ( $\mathrm{rad} / \mathrm{Sec})$. \\
\hline $\begin{array}{l}P_{o} \\
\Delta P\end{array}$ & $\begin{array}{l}\text { Pressure at the outlet section, }(\mathrm{Pa}) \text {. } \\
\text { Pressure drop, }(\mathrm{Pa}) \text {. }\end{array}$ & $\beta$ & $\begin{array}{l}\text { Angle of channel orientation with } \\
\text { respect to the axis of rotation. }\end{array}$ \\
\hline
\end{tabular}

\section{Introduction}

Modern gas turbine blades are designed to operate at increasingly higher inlet temperatures to improve turbine thermal efficiency. To maintain acceptable blade life, sophisticated cooling techniques such as film cooling, impingement cooling or convective internal cooling are essential. Rotation of turbine blade cooling passages gives rise to Coriolis and buoyancy forces that can significantly alter the local heat transfer in the internal coolant passages due to the development of cross stream (Coriolis) as well as radial (buoyant) secondary flows. Typically, the coolant flows through a series of straight ducts connected by $180^{\circ}$ turns and roughened with ribs or pin fins. These cooling ducts may not only be square in cross-section; the aerodynamic shape of the turbine blade dictates the use of cooling channels that are rectangular in cross-section (with different aspect ratios). The 
investigation of the flow and heat transfer in these ducts is especially important for the design of the cooling passage. The intention of this study is to facilitate a comprehensive understanding of the characteristics of flow and heat transfer in these ducts through numerical prediction. Some experimental and numerical studies have been conducted in this field. Our review is restricted to the turbulent flow and heat transfer studies in rotating and non-rotating coolant passages with smooth walls.

Han et al. [1] chronicled many studies that began with non rotating channels with and without rib turbulators. The size, shape, and placement of the turbulators were varied to determine the optimal design for the given flow conditions. Fu. [2], investigated the effects of rotation, the buoyancy force, and the channel aspect ratio on heat transfer in two-pass rotating rectangular channels. The experiments were conducted with two surface conditions: smooth walls and $45^{\circ}$ angled ribbed walls. The channel aspect ratios included 4:1, 2:1, 1:1, 1:2 and 1:4. Four Reynolds numbers were studied: 5000, 10000, 25000 and 40000. The rotation speed was fixed at $550 \mathrm{rpm}$ for all tests, and for each channel, two channel orientations were studied: $90^{\circ}$ and $135^{\circ}$. K.Arun and Prabho [3], carried out an experimental investigation of the effects of aspect ratio, channel orientation angle, rib pitch-to-height ratio $(P / e)$, and number of ribbed walls on friction factor in orthogonally rotating channel with detached ribs. The ribs were separated from the base wall to provide a small region of flow between the base wall and the ribs. Yao-Hsien [4], tested the heat transfer enhancement in a channel for different spacing of the rib turbulators. Those ribs were put on the surface in the two pass rectangular channel with an aspect ratio of $A R=1: 2$. Al-Hadhrami et al [5], studied the effect of parallel and crossed $45^{\circ}$ angled rib turbulator arrangements on the Nusselt number ratio in a rotating, two pass, square channel for three Reynolds numbers (5000, 10000,25000 ), with rotation number up to 0.11 , and two channel orientations with respect to the axis of rotation $\left(\beta=90^{\circ}\right.$ and $135^{\circ}$ ). In the study of Liou et al. [6], an experimental study of heat transfer in a radially rotating rectangular channel of aspect ratio 1:2 with two opposite walls roughened by $45^{\circ}$ staggered ribs was performed. Heat transfer distributions along centerlines of two rib- roughened surfaces were measured for the radially outward airflow at test conditions of Reynolds number (Re), rotation number (Ro) and density ratio $(\Delta \rho / \rho)$ in the ranges of 5000 $15,000,0-2$ and $0.07-0.28$. In the study of Liou and Chen [7], measurements of the distributions of heat transfer coefficients along the leading and trailing walls of a rotating two-pass rectangular channel with through flow was done. The channel a $180^{\circ}$ 
M. 70 Sabry M. Ragab, Ahmed A. Sultan, L. H. Rabee and Moh El-Naggar

rectangular had turn and a cross-sectional aspect ratio of 1.25. The Reynolds number and rotational number were varied from $5 * 10^{3}$ to $5 * 10^{4}$ and 0 to 0.44 , respectively. Han and Chen [8],

performed rotating heat transfer in high aspect ratio rectangular cooling passages with shaped turbulators, The results show that rotation significantly increases the Nusselt number ratio on the first pass trailing surface and the second pass leading surface. The rotating Nusselt number ratios on the first pass trailing and second pass leading surfaces are higher than in the non-rotating case. The broken 45-deg V-Shaped ribs provide better heat transfer enhancement than the V-Shaped ribs and the broken 45 deg angled ribs. The effect of channel orientation is fairly small for the low rotation number cases considered.

Han and Ligrani [9], studied the rotating and stationary rectangular cooling passage heat transfer and friction with ribs, pins and dimples. The results show that spanwise heat transfer has differences of up to $25 \%$ for the smooth tilted channel and $50-75 \%$ for the ribbed channel exist across the leading and trailing surfaces.

Al-Qahtani et al. [10], performed a Numerical prediction of three-dimensional turbulent flow and heat transfer for a rotating two-pass smooth rectangular channel with channel aspect ratio of $2: 1$. The focus of this study was to investigate the effect of rotation, channel orientation and the sharp $180^{\circ}$ turn on the flow and heat transfer distributions, The results show that the Nusselt number ratios on the first passage trailing and second passage leading surfaces increase with an increase in the rotation number and density ratio.

Han and Lesley [11], studied the effect of rotation, channel orientation and flow field measurements in rotating cooling channels. Results show that turbulent heat transfer in a stationary pin-fin channel can be enhanced up to 3.8 times that of a smooth channel; rotation enhances the heat

transferred from the pin-fin channels up to 1.5 times that of the stationary pin-fin channels. Al-Qahtani et al. [12], [14] performed numerical prediction threedimensional turbulent flow and heat transfer in a rotating rectangular channel

with aspect ratio (AR) of $10: 1$, oriented at $90^{\circ}$ and $120^{\circ}$ from the direction of rotation.

The results show that Nusselt number ratios on the first passage trailing and second passage leading surfaces increase with an increase in the rotation number and density ratio.

Mehaboob Basha [13], performed The effects of rotation and coolant-to-wall density ratio on the fluid flow and heat transfer characteristics are reported on a moderate range of rotation numbers and density ratios $\left(0<R_{0}<0.25\right.$ and $0.07<\Delta \rho / \rho$ $<0.4)$. The results show that; In $\beta=90^{\circ}$ case, 
Nusselt number decreases with increase in density ratio, for fixed rotation number. In $\beta$ $=120^{\circ}$ case, Nusselt number increase with increase in rotation number as well as density ratio.

Hamn-Ching Chen et al [15], [16] Numerical predictions of three-dimensional flow and heat transfer are presented for a rotating twopass rectangular channel with 45-deg rib turbulators and channel aspect ratio of 2:1. The secondary flow results in steep temperature gradients and high heat transfer coefficients on both the inner and ribbed surfaces (for the first passage) and on both the outer and ribbed surfaces (for the second passage).

\section{Description of the Problem}

Calculations were performed for a rotating and non-rotating two pass rectangular channel with smooth surface. A schematic diagram of the problem investigated in this study is shown in Figure 1. The channel has a rectangular cross section with a channel aspect ratio $(A R)$ of $2: 1$ and $1: 2$. Two of the four side walls, the two in the rotational direction are denoted as leading and trailing surfaces, while the other two are denoted as inner and outer surfaces. The length of both the first pass (part1) and second pass (part3) were $126.75 \mathrm{~mm}$. The distance from the inlet of the channel to the axis of rotation (Y-axis) is given by $R=338 \mathrm{~mm}$. Each passage consists of an unheated and a heated section.
The length of the unheated section was 217 $\mathrm{mm}$. The arc length $(S)$ is measured from the beginning of the heated section in the first passage to the end of the heated section in the second passage. The total length of the channel, $L$, equals to $375.5 \mathrm{~mm}$. The channel hydraulic diameter, $D_{h}$, is $(16.9 \mathrm{~mm})$. The radius of curvature of the $180^{\circ}$ sharp turn was $6.35 \mathrm{~mm}$. The channel is made up of two straight passages and a $180^{\circ}$ sharp turn (part2). All walls were heated to a constant temperature. In this study, the Reynolds number (Re) was varied from 19000 to 25000. The rotation number (Ro) is varied from ( 0.0 to 0.1$)$, and inlet coolant-to-wall density ratios $(\Delta \rho / \rho)=0.39$.

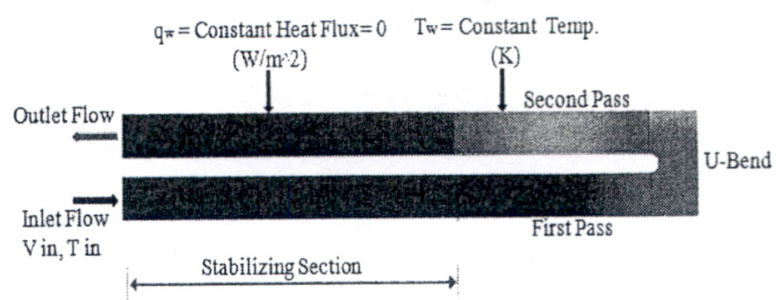

Fig.1.(a), the boundary conditions used in CFD model (Conceptual view cross section)

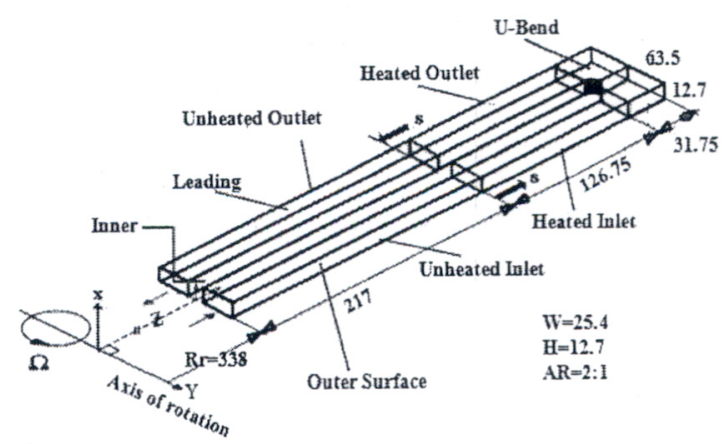

Fig.1.(b),Smooth internal cooling channel. (Geometry of the $\mathrm{AR}=2: 1$ ) 


\section{72 Sabry M. Ragab, Ahmed A. Sultan, L. H. Rabee and Moh El-Naggar}

\subsection{Boundary Conditions}

Figure (1.a) summarizes the boundary conditions used in the model. At the inlet to the channel, the flow conditions are assumed to be fully developed. In order to apply a fully developed flow boundary condition, at the inlet of the two-pass channel, velocity, temperature and turbulence profiles were mapped from the outlet of a periodic segment to the inlet of the two-pass channel. This periodic segment ensures that the flow is fully developed. The inlet mass flow rate for the periodic segment corresponds to the Reynolds number which varied from 19,000 to 25,500 ; with the inlet temperature of 773 K. Turbulence intensity varied from 4.5 to $4.66 \%$ was used at the inlet. This was calculated by the relationship provided by ANSYS Fluent 12.0, Theory Guide shown as the follow: $I=0.16 R e^{-1 / 8}$

All walls were kept at a constant temperature of $1273 \mathrm{~K}$. Symmetry was introduced at the top of the computational domain shown in Figure (1.a), which reduces the computational effort.

The flow is considered incompressible, three dimensional, turbulent and steady with constant thermodynamic properties. The working fluid is dry air with Prandtl number equal to 0.71 . Ideal gas law is used to calculate density variation with temperature. The grid independence study and validations of numerical results for both types of channels are presented separately.

Table (1) shows the used boundary conditions.

\begin{tabular}{|c|c|c|c|}
\hline Boundary & $\begin{array}{c}\text { tneulF } \\
\text { yradnuob } \\
\text { condition }\end{array}$ & Input & \\
\hline \multirow{2}{*}{$\begin{array}{l}\text { Inlet } \\
\text { Section }\end{array}$} & $\begin{array}{c}\text { Inlet } \\
\text { velocity }\end{array}$ & Vin & $\begin{array}{c}90-120 \\
(\mathrm{~m} / \mathrm{s})\end{array}$ \\
\hline & $\begin{array}{c}\text { Inlet } \\
\text { temperature }\end{array}$ & Tin & $773(\mathrm{k})$ \\
\hline \multirow{2}{*}{$\begin{array}{c}\text { Stabilizing } \\
\text { section } \\
\text { (Unheated } \\
\text { Wall) }\end{array}$} & Wall & \multicolumn{2}{|c|}{$\begin{array}{c}\mathrm{q}_{\mathrm{w}}=\underset{\mathrm{Heat}}{\mathrm{H} f \mathrm{u}} / \mathrm{m}^{2} \\
\end{array}$} \\
\hline & Wall & \multicolumn{2}{|c|}{$\begin{array}{c}\mathrm{q}_{\mathrm{w}}=\text { Heat flux } \\
\mathrm{w} / \mathrm{m}^{2}\end{array}$} \\
\hline $\begin{array}{l}\text { Heated } \\
\text { Inlet }\end{array}$ & Wall & $\begin{array}{c}T_{w}=T( \\
k)\end{array}$ & $1273(\mathrm{k})$ \\
\hline U-Bend & Wall & $\begin{array}{c}T_{w}=T( \\
k)\end{array}$ & $1273(k)$ \\
\hline $\begin{array}{l}\text { Heated } \\
\text { Outlet }\end{array}$ & Wall & $\begin{array}{c}T_{w}=T( \\
k)\end{array}$ & $1273(\mathrm{k})$ \\
\hline $\begin{array}{l}\text { Outlet } \\
\text { Section }\end{array}$ & $\begin{array}{l}\text { Pressure } \\
\text { Outlet }\end{array}$ & \multicolumn{2}{|c|}{$\begin{array}{l}\text { Zero normal gradient } \\
\text { for all flow variables }\end{array}$} \\
\hline
\end{tabular}

\section{Theoretical Work}

\subsection{Governing Equations}

The continuity, momentum and energy equations for a Newtonian incompressible fluid are given as:

$$
\frac{\partial \rho}{\partial t}+\frac{\partial \rho U_{1}}{\partial x_{i}}=0
$$

$\frac{\partial \rho U_{i}}{\partial t}+\frac{\partial \rho U_{i} U_{i}}{\partial x_{i}}=\rho g_{1}+F_{i}-\frac{\partial P}{\partial x_{i}}+\frac{\partial}{\partial x_{i}}\left(2 \mu S_{t j}\right)$

$$
\begin{aligned}
& \frac{\partial \rho E_{o}}{\partial t}+\frac{\partial \rho U_{i} E_{o}}{\partial x_{i}} \\
& =\rho U_{i} F_{i}-\frac{\partial q_{i}}{\partial x_{i}}+\frac{\partial}{\partial x_{j}}\left(U_{i} T_{i j}\right)
\end{aligned}
$$


Where $F_{i}$ are the additional body-forces that affect the fluid motion such as rotation, magnetic or electric field etc., and $\mathrm{S}_{\mathrm{ij}}$ is the strain rate tensor, $T_{i j}$ are the surface forces similar to the viscous and pressure terms in the momentum equations $\left(T_{i j}=-P \delta_{i j}+\tau_{i j}\right)$ and $E_{\mathrm{o}}$ is the total internal energy.

Assuming constant rotation velocity the extra terms due to rotation (body-force modification to the $\mathrm{N}-\mathrm{S}$ equations) are:

$$
\begin{aligned}
& a_{i}^{c e}=\varepsilon_{i j k} \varepsilon_{k l m} \Omega_{j} \Omega_{l} x_{m} \\
& \alpha_{i}^{c o}=2 \varepsilon_{i j k} \Omega_{j} U_{k}
\end{aligned}
$$

\subsection{Two-Equation $k-\varepsilon \quad$ Turbulence Models}

In this study the two-equations [Standard k- $\varepsilon$ Model] are considered (which are available in FLUENT CFD Code [19]).

\subsection{Numerical Modeling}

FLUENT ANSYS 6.3.26 code was used to simulate and solve these heat transfer problem. The first step of solving this problem is the geometrical configuration which is established by the fluent drawing tool known as GAMBIT which used to create the model. A three dimensional model was used to solve this problem. The first step of drawing the three dimensional model was creating the boundary points and connecting these boundaries to develop edges after that the face which to connect the whole edges. The geometrical configuration is meshed and then the mesh exported to FLUENT code.
The boundary conditions were entered into the code and the program solved the governing equations at each node in the face until reaching an arbitrary error less than $10^{-5}, 10^{-7}$ for energy equation. The solution was considered to have converged when all of the scaled residual have become less than or equal to the above set value. Fig. (2.a) shows the duct geometry and the numerical grid generated using GAMBIT grid generator [20], for this study.

The geometry and the gird were generated using GAMBIT the preprocessing module of the FLUENT version 6.3.26. GAMBIT is an integrated preprocessor for CFD analysis. The sequences of steps involved in GAMBIT are shown in Fig. (2.b). After the geometry exported to FLUENT 6.3.26 then the problem specification scale, boundary conditions, solution, and errors are entered to fluent according to the present problem. Fig. (2.c) shows the steps involved in solving the problem in fluent.

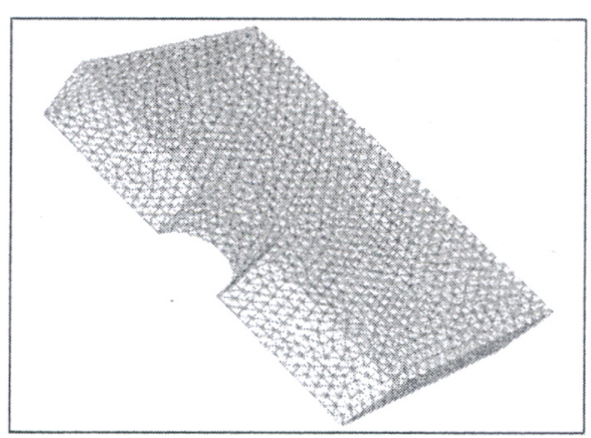

Fig. (2.a) Computational grid of two-pass rectangular channel with smooth walls. 
M. 74 Sabry M. Ragab, Ahmed A. Sultan, L. H. Rabee and Moh El-Naggar

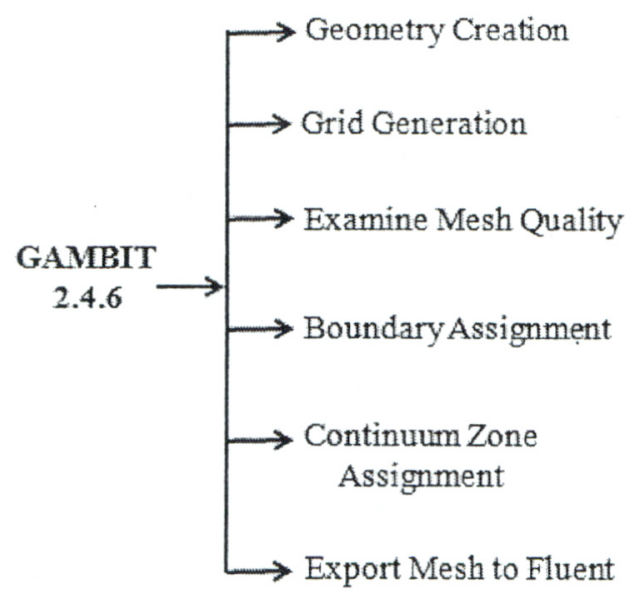

Fig.(2.b) Steps involved in exporting mesh file from GAMBIT.

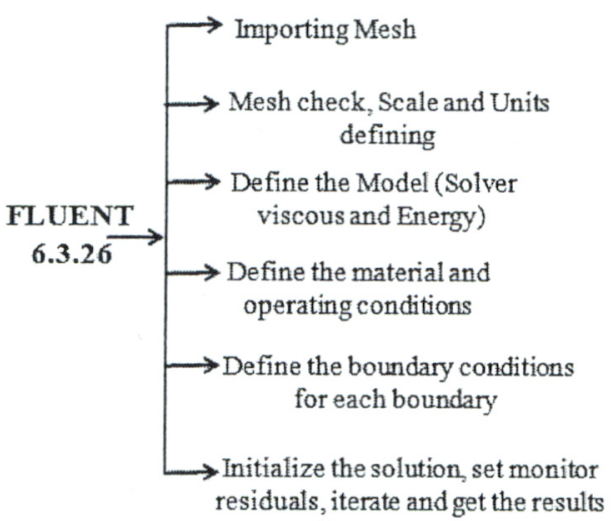

Fig. (2.c) the steps involved in solving the problem in FLUENT

\section{Data Reduction}

\subsection{Heat Transfer Coefficient}

This study investigates the regionally averaged heat transfer coefficient at various locations within the rotating and stationary ducts. The heat transfer coefficient is determined by the net heat transferred from the heated wall, the surface area of the walls and the regionally averaged temperature of the wall.
Therefore, the heat transfer coefficient is given as:

$$
h=\frac{Q / A_{s t w}}{\left(T_{11}-T_{f, \text { ave }}\right)}
$$

Where:

$Q=\dot{m} C p\left(T_{o t t}-T_{m}\right), \quad T_{\text {fave }}=\left(\frac{T_{m}+T_{\text {omt }}}{2}\right)$,

$\mathrm{A}_{\text {sur }}=$ Surface area, $\mathrm{T}_{\mathrm{w}}=$ Wall temperature.

The Dittus_Boelter correlation [2], for heating $\left(T_{w, x}>T_{f, x}\right)$ is used in this study to provide a basis of comparison. The Dittus_Boelter correlation is used to calculate the Nusselt number for fully developed turbulent flow through a smooth stationary circular tube [2] and [7]. Therefore, the Nusselt number is given as:

$$
N u_{o}=0.023 \operatorname{Re}^{0.8} \operatorname{Pr}^{0.4}
$$

While local Nusselt number is given as:

$$
N u=h D_{h} / k
$$

\subsection{Frictional Losses}

The frictional losses in the cooling channel are determined by calculating the pressure drop from the inlet to the outlet of the heated test section. The friction factor is calculated using the values of the inlet and outlet pressures correlated by Dittus_Boelter [2], as :

$$
f=\frac{P_{i-} P_{o}}{4\left(\frac{L}{D_{h}}\right)\left(\frac{1}{2} \rho V^{2}\right)}
$$

The turbulent friction factor in a smooth tube as given by the Blasius equation is:

$$
f_{o}=0.079 R e^{-0.25}
$$




\subsection{Thermal Performance}

Based on the heat transfer enhancement $\left(\mathrm{Nu} / \mathrm{Nu}_{0}\right)$ and the pressure loss penalty $\left(f / f_{0}\right)$, the thermal performance, $\eta$, of each channel can be calculated. Equation (11) shows the thermal performance based on the constant pumping power condition as used by Fu et al. [2].

$$
\eta=\frac{N u / N u_{o}}{\left(f / f_{o}\right)^{1 / 3}}
$$

\section{Results and Discussion}

The aim of the present study is divided into two objectives, using a validated Reynolds Averaged Navier Stokes (RANS) turbulence model method to predict threedimensional flow and heat transfer in a stationary and rotating two-pass rectangular channel with aspect ratios equal to $2: 1$ and $1: 2$.

\subsection{Heat Transfer in Stationary \\ Channels.}

As mentioned earlier, the target zone in all predicted configurations is divided into three areas as shown in Fig. (1) $(a, b)$ where Nusselt Numbers were obtained for each of those areas. For all the cases, those Nusselt Numbers were plotted versus the Reynolds Numbers.

\subsection{Model Validation}

In order to validate the results of CFD model used in the present study, comparison between mean Nusselt number and friction factor of the present study and experiment data of Fu et al [2] in case of smooth rectangular duct was done.
The comparison between experimental data and predicted values of Nusselt number and friction factor are shown in Fig.(3. a, b), respectively. The agreement is seen to be reasonably good. The above comparison ensures the accuracy of computational results proposed to be obtained from the present study. The figure shows that the difference in present $\mathrm{Nu}$ was about $(2.19 \%)$ at lower values of Reynolds number and (3.1\%) at higher values of Reynolds number, while the friction factor was about $(2.89 \%)$ at lower values of Reynolds number and (4.3\%) at higher values of Reynolds number. This may attributed to the difference between the experimental and numerical inlet boundary conditions.
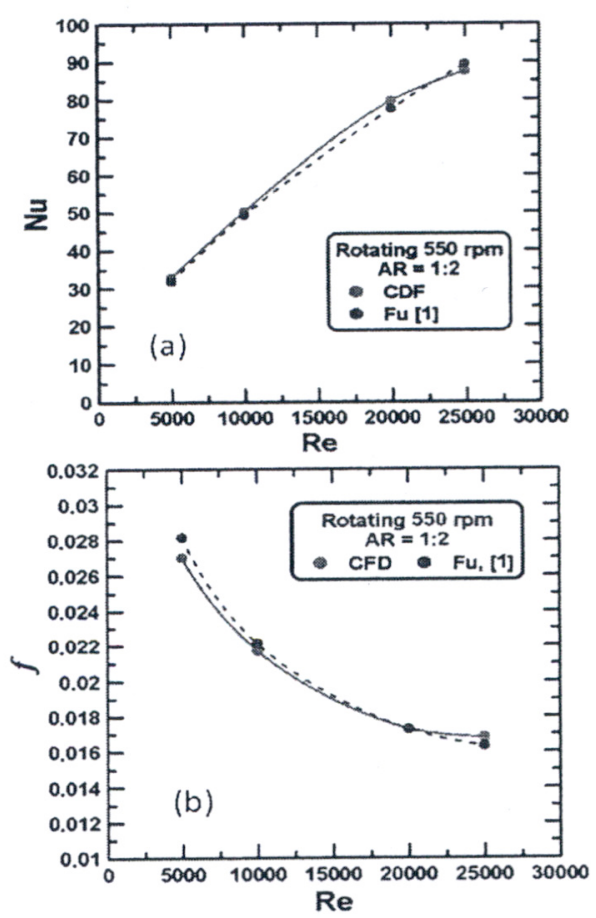

Fig. (3), Model Validation in rotating Smooth rectangular channel at various values of Re vs. Nu and $f$. 
M. 76 Sabry M. Ragab, Ahmed A. Sultan, L. H. Rabee and Moh El-Naggar

\subsection{Stationary Case}

\subsubsection{Results of stationary channels}

In order to determine the effect of channel rotation, we will firstly demonstrate the results of stationary channels. The results of $\mathrm{Nu}$ distribution $\left(\mathrm{Nu}_{\mathrm{x}}\right)$ is presented at first followed by the results of mean Nusselt Number $(\mathrm{Nu})$, the result of friction factor $(f)$ and finally the results of thermal efficiency $(\eta)$.

\subsubsection{Streamwise Nu distributions}

Fig. (4) shows the relation between local Nusselt number and dimensionless distance from the beginning of the channel under consideration $\left(\mathrm{X} / \mathrm{D}_{\mathrm{h}}\right)$ for aspect ratios of $1: 2$ \& 2:1 and Reynolds number equal to $18860,21000,23000$ and 25000. From the overview of the figures one can observe that $\mathrm{Nu}_{\mathrm{x}}$ increases with $\mathrm{Re}$ along the channel length and the shape of $\mathrm{Nu}_{\mathrm{x}}$ versus $\mathrm{X} / \mathrm{D}_{\mathrm{h}}$ at different Re is nearly preserved. It is shown from the figures that $\mathrm{Nu}_{\mathrm{x}}$ first decreases with increasing $\mathrm{X} / \mathrm{D}_{\mathrm{h}}$ indicating a developing flow at $\mathrm{X} / \mathrm{D}_{\mathrm{h}} \leq 6.25$ approaches the fully developed value at $\mathrm{X} / \mathrm{D}_{\mathrm{h}}=6.25$ and $\mathrm{Nu}_{\mathrm{x}}$ remains nearly constant until $\mathrm{X} / \mathrm{D}_{\mathrm{h}}=7.5$ at the end of part 1. As air inters the sharp UTurn $\mathrm{Nu}_{\mathrm{x}}$ increases due to the upstream effect of the turn until $\mathrm{X} / \mathrm{D}_{\mathrm{h}}=8.25$ for $A R=2: 1$ (the (the beginning of U-turn).
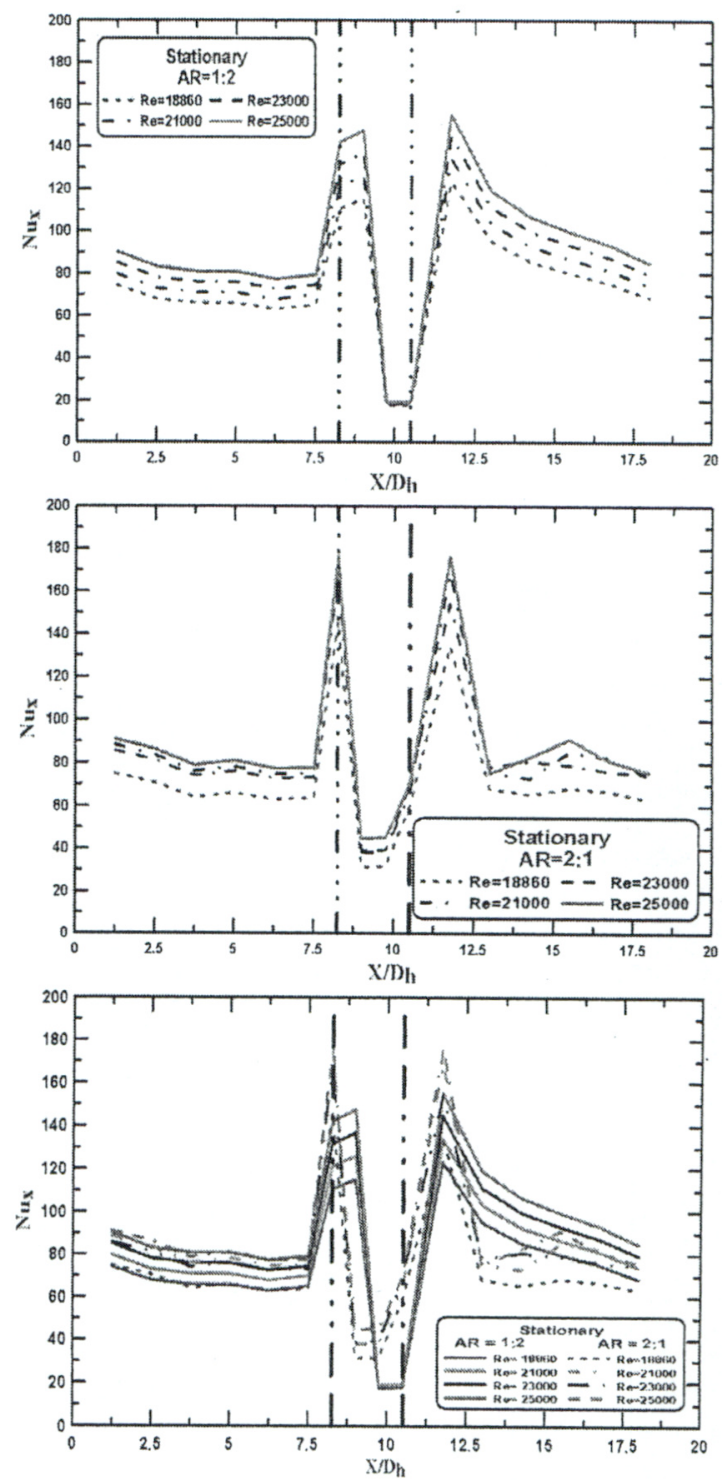

Fig. (4) Streamwise Nu distributions in two pass stationary duct at various values of Re and AR.

The decrease of $\mathrm{Nu}_{\mathrm{x}}$ in first part of U-Turn may be due to flow separation from the channel wall, while the increase of $\mathrm{Nu}_{\mathrm{x}}$ in the second part of U- turn, may be due to the vortex generated through the channel which makes is a good fluid mixing. 
At the inlet section of part $3, \mathrm{X} / \mathrm{D}_{\mathrm{h}}$ varies from 10.5 to $11.75, \mathrm{Nu}_{\mathrm{x}}$ increases sharply to maximum values, depending on Reynolds Number at $X / D_{h}=11.75$. This sudden increase is may be due to boundary layer disturbance in the $180^{\circ}$ U-Turn. Finally, through the remaining section of part $3, \mathrm{Nu}_{\mathrm{x}}$ decrease with the increase of $X / D_{h}$ which may be due to the developing flow through this passage.

\subsubsection{Mean Nusselt number}

Figure $(5 . a, b, c)$ show the relation between mean $\mathrm{Nu}$ and $\mathrm{Re}$ for rectangular channels with aspect ratio of 2:1 and 1:2. Four group of results are presented in figure (5). The first group of results concerning the mean $\mathrm{Nu}$ over the first pass (part 1), while the second group of results concerning the mean $\mathrm{Nu}$ over the second pass of channel, named as (part 2). The third group of results concerning the mean Nusselt number over the third pass (part 3), while the fourth group concerning the mean Nusselt number over the entire channel including the three parts.

One can observe from figure (5) that mean $\mathrm{Nu}$ increase with Re for all the three parts at different aspect ratio. Figure (5.c) shows the comparison between values of mean Nusselt number for different parts. It is shown from the figure that mean $\mathrm{Nu}$ of part (1) for $A R=2: 1$ is higher than that for $A R=1: 2$. The mean $\mathrm{Nu}$ of all parts for $\mathrm{AR}=1: 2$ are higher than that for $\mathrm{AR}=2: 1$.
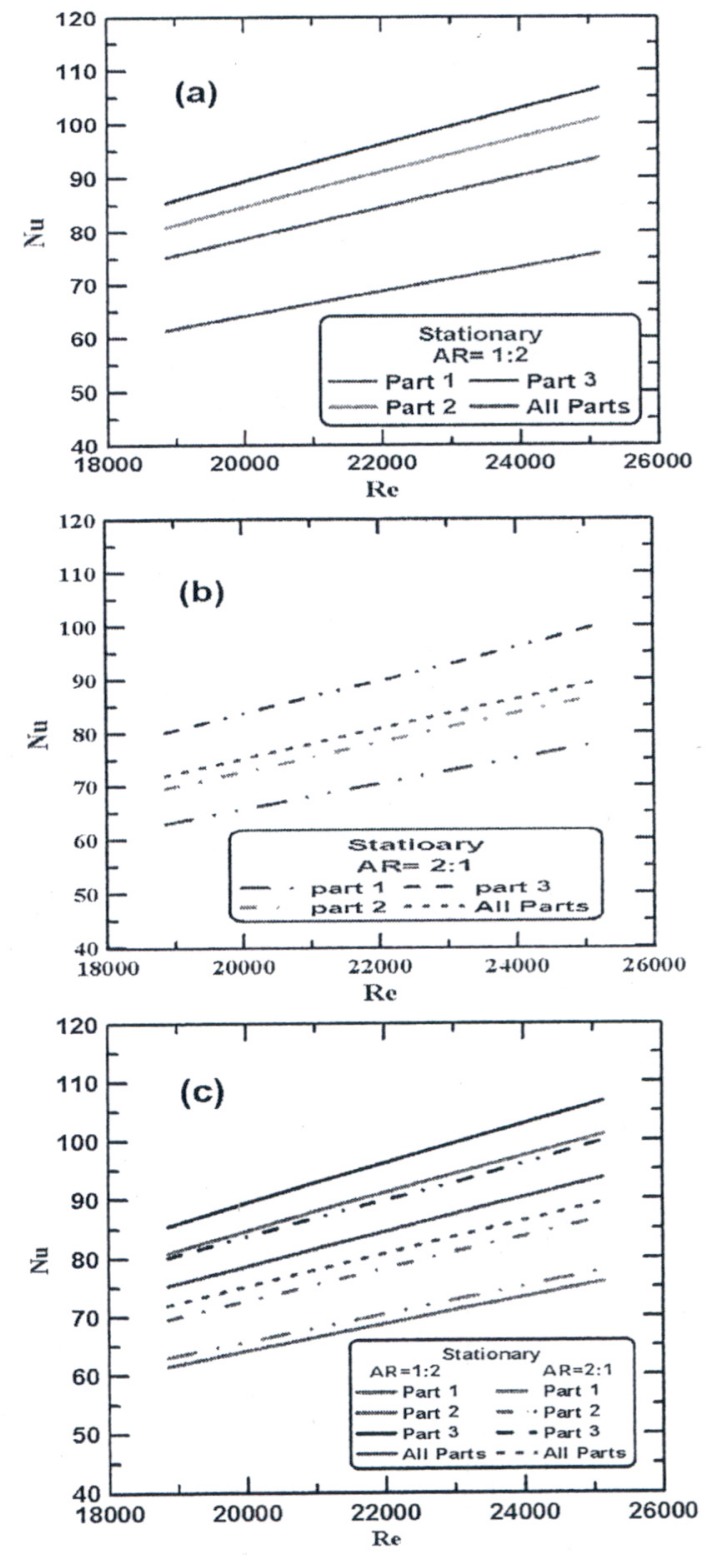

Fig. (5) Nusselt Number versus Reynolds Number for two pass stationary channel

\subsubsection{Friction Factor Results}

Figure (6) shows the relation between mean friction factor $(f)$ and Reynolds number $(\mathrm{Re})$ for the present study and the data of Blasius equation (13). It is seen from the figure that $(f)$ for part (2) is higher than that of $(f)$ for part (1) and part (3). Results of $(f)$ for part (2) is higher than Blasius values while the results of $(f)$ for part (1) and part 


\section{78 Sabry M. Ragab, Ahmed A. Sultan, L. H. Rabee and Moh El-Naggar}

(3) are higher than Blasius values. The figure also shows a fair agreement between the friction factor results of part (1) (inlet passage) and the values of Blasius correlation and the deviation within $(33 \%$ for $A R=2: 1)$ and $(13.6 \%$ for $A R=1: 2)$. This seems to be normal due to the difference in configurations of the two channels.
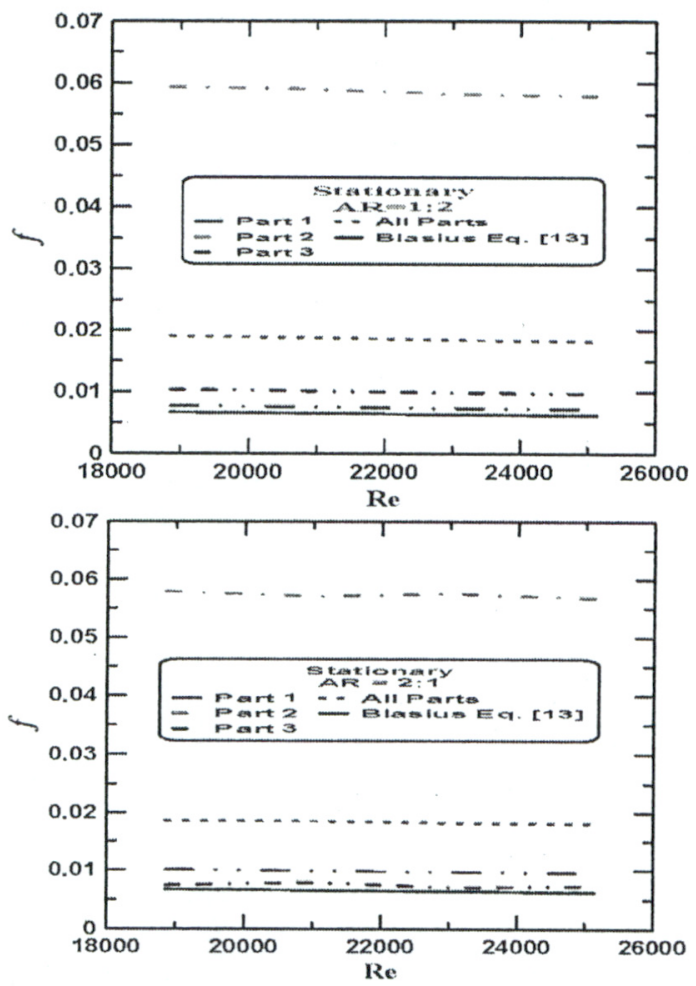

Fig. (6) Friction factor vs. Reynolds number for stationary smooth channel

\subsubsection{Thermal performance results}

Figure (7) indicates the relation between the complex $\left(\mathrm{Nu} / \mathrm{Nu}_{0}\right) /\left(f / f_{0}\right)^{1 / 3}$ signed as $(\eta)$ and Reynolds number for every part Separately and the whole channel including all three parts in case of $A R=1: 2$ and $A R=2: 1$. It is seen from the figure that $(\eta)$ for $A R=1: 2$ is higher than that of $(\eta)$ for $A R=2: 1$ with a deviation about ( $6.65 \%)$. Also it is seen that ( $)$ decreases as Reynolds increases with all the values of $(\eta)$ higher than unity which mean an enhancements in heat transfer with minimum pumping power.
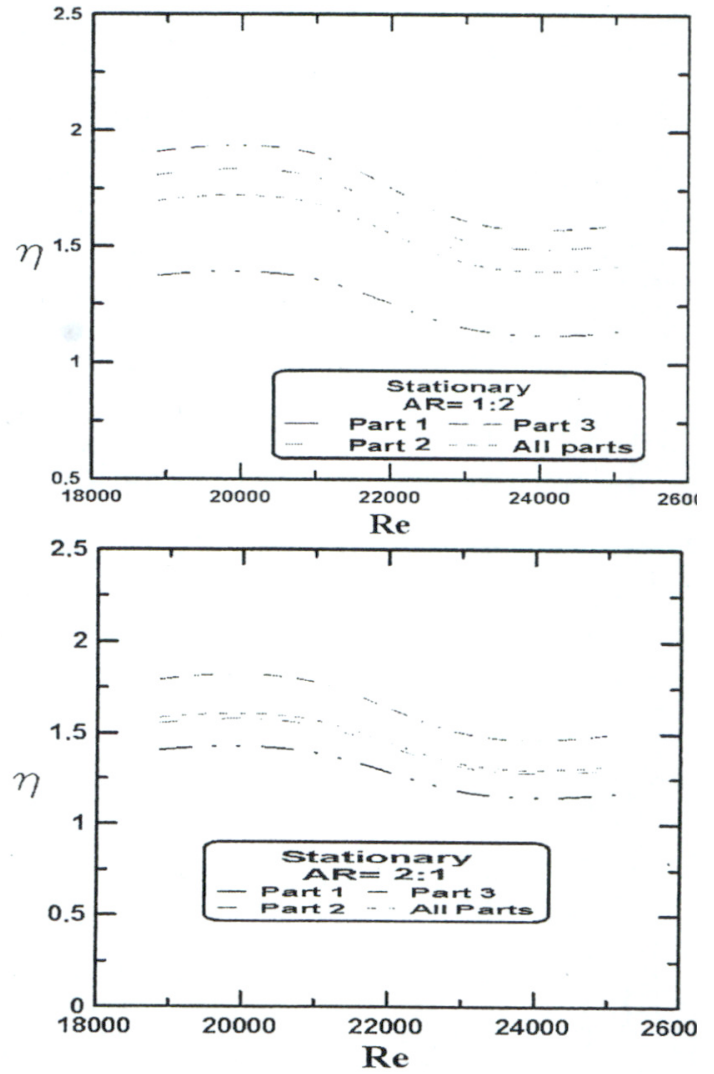

Fig. (7) Thermal Performance vs. Reynolds number for smooth stationary channel

\subsection{Rotating Case}

\subsubsection{Results of Rotating Channels}

In this section the results of local Nusselt number $\left(\mathrm{Nu}_{\mathrm{x}}\right)$, mean Nusselt number $(\mathrm{Nu})$, friction factor $(f)$ and thermal efficiency are presented for different Re and AR.

\subsubsection{Local Nusselt results}

The relation between $\mathrm{Nu}_{\mathrm{x}}$ and $\mathrm{X} / \mathrm{D}_{\mathrm{h}}$ at different aspect ratio, different Reynolds number and different speed of rotation are illustrated in figure (8\&9). 
The results of figure (8) concerning the channel of $A R=1: 2$. From this figure we can see that $\mathrm{Nu}_{x}$ decreases with $\left(\mathrm{X} / \mathrm{D}_{\mathrm{h}}\right)$ through part (1) of the channel, indicating a developing flow in the thermal entry length and then increases near the end of the first passage $\left(X / D_{h}=6.25\right)$ because of the upstream effect of the turn. At the beginning of part (2) (U-turn) $\mathrm{Nu}_{\mathrm{x}}$ increases with $\mathrm{X} / \mathrm{D}_{\mathrm{h}}$ until the flow reaches a value of $\mathrm{X} / \mathrm{D}_{\mathrm{h}}=$ (9) because of the upstream effect of the turn. Following through the U-turn (part 2) behind $\mathrm{X} / \mathrm{D}_{\mathrm{h}}=(9), \mathrm{Nu}_{\mathrm{x}}$ decreases again from $X / D_{h}=$ (9) to $\mathrm{X} / \mathrm{D}_{\mathrm{h}}=(9.75)$ nearly the half of the Uturn and increases again during the second half $\left(X / D_{h}=(11.75)\right.$. The figure shows also that $\mathrm{Nu}_{\mathrm{x}}$ continues increasing up to $\mathrm{X} / \mathrm{D}_{\mathrm{h}}=(11.75)$. It may be due to swirl transfer through this portion. Through $\mathrm{X} / \mathrm{D}_{\mathrm{h}}=(13)$ to the end of part (3) a developing flow exist again making $\mathrm{Nu}_{\mathrm{x}}$ decreases with $\mathrm{X} / \mathrm{D}_{\mathrm{h}}$ to the end of part (3) (end of the channel).

Figure (8\&9) indicate that the same $\mathrm{Nu}_{\mathrm{x}}$ distribution trend nearly exists with different Re, different $A R$ and different speed of rotation.

Comparing the results of all curves drawn in figure $(8,9)$ one can conclude that $\mathrm{Nu}_{\mathrm{x}}$ increases with $\mathrm{Re}$ and rotation speed for the same $A R$, and the channel with $A R=2: 1$ indicates higher values of $\mathrm{Nu}_{\mathrm{x}}$ that these of the channel with $\mathrm{AR}=1: 2$.
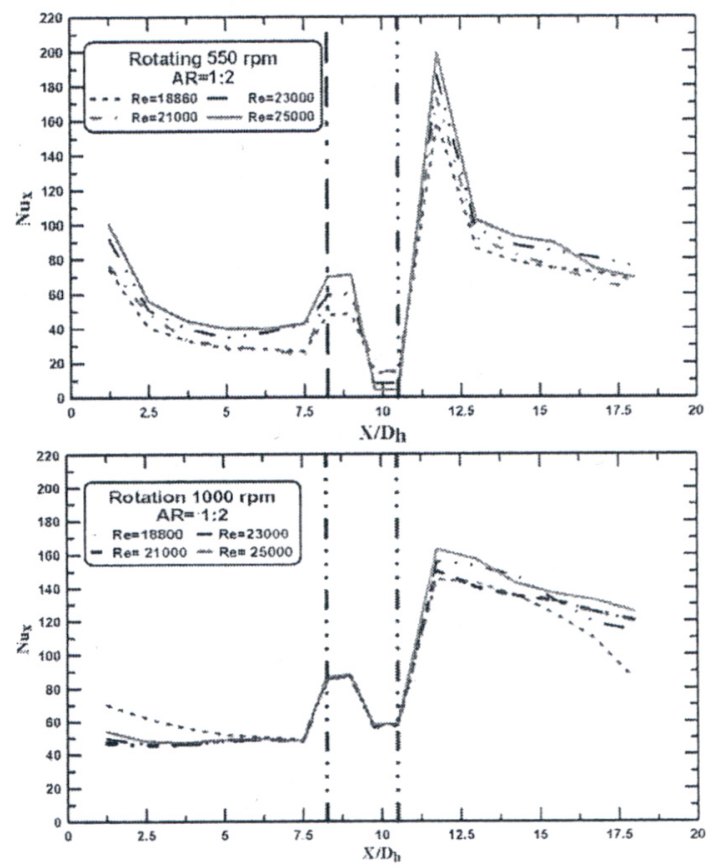

Fig. (8) $\mathrm{Nu}_{\mathrm{x}}$ versus $\mathrm{X} / \mathrm{D}_{\mathrm{h}}$ at various values of Re and rotational speed, $A R=1: 2$
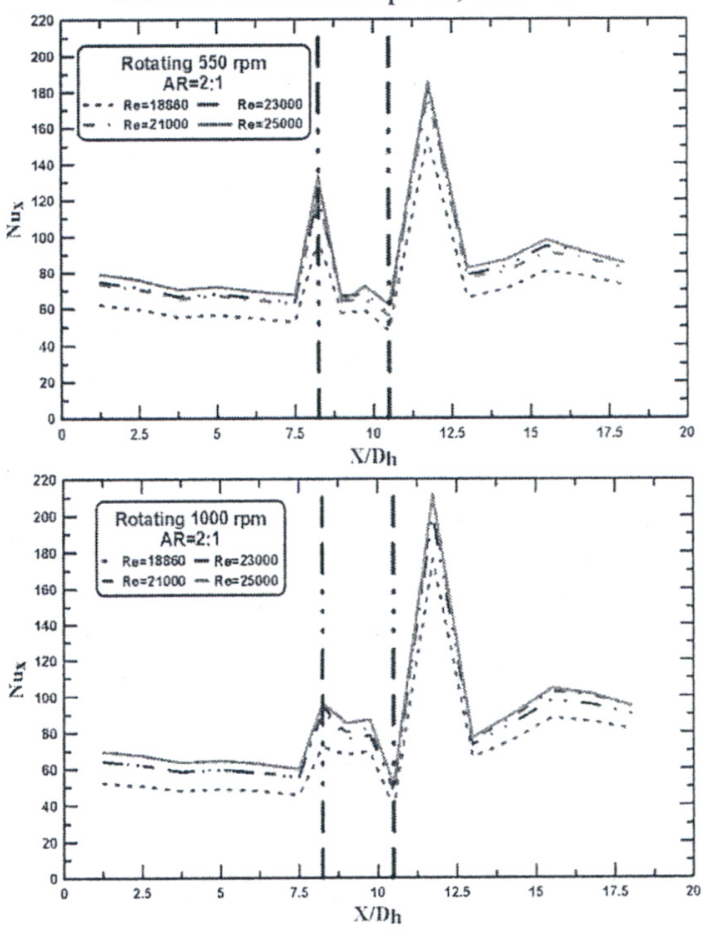

Fig. (9) $N u_{x}$ versus $X / D_{h}$ at various values of $\mathrm{Re}$ and rotational speed, $\mathrm{AR}=2: 1$ 


\section{80 Sabry M. Ragab, Ahmed A. Sultan, L. H. Rabee and Moh El-Naggar}

\subsubsection{Averaged Nusselt number}

The averaged Nusselt number for the rotating channels are shown in Fig.(10) and Fig. (11). For different aspect ratios $(A R=2: 1),(A R=1: 2)$ and different rotation speeds. In all parts, Nusselt number increases with Reynolds number for both AR. This behavior is expected also because when the mass flow rate increases, the convective effects of the flow also increase so Nusselt number increases.

Comparison between the two aspect ratio cases at rotational speed $(\mathrm{N})$ of $550 \mathrm{rpm}$ as shown in Fig.(10), leads to the flowing: In parts $(1,2,3)$, Nusselt number is higher in case of $A R=2: 1$ than in case of $A R=1: 2$. In the whole channel, Nusselt number is higher in case of $\mathrm{AR}=2: 1$ than in case of $A R=1: 2$. Generally, The highest Nusselt number is predicted in the second pass (part (3)) than the other parts.

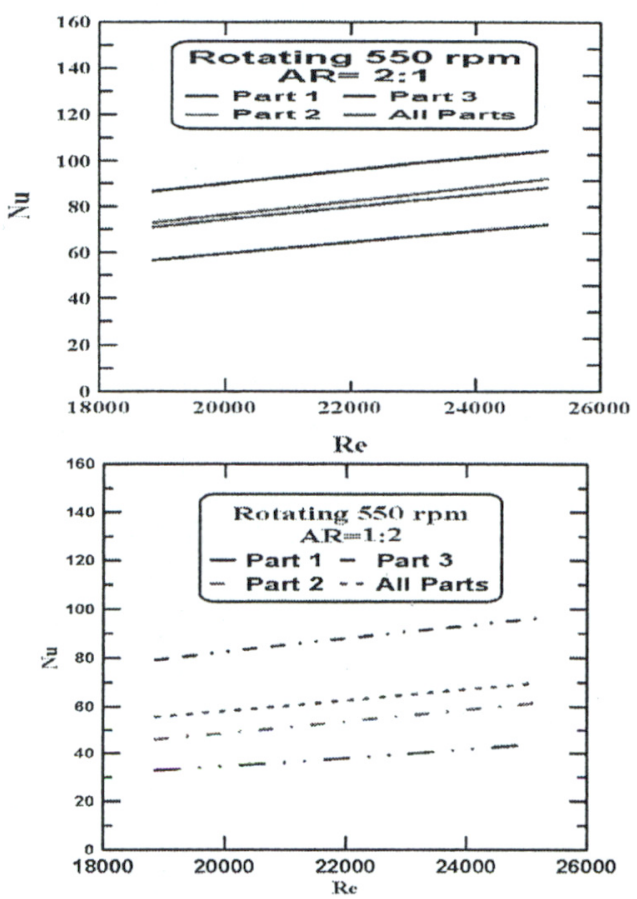

Fig. (10) Average Nusselt Number versus Reynolds Number for two pass Rotating channel.
Comparison between the two aspect ratio cases at rotational speed (N) $1000 \mathrm{rpm}$, leads to the flowing:

In part (1), Nusselt number is higher in case of $A R=2: 1$ than in case of $A R=1: 2$ as shown in Fig.(11). In part (2), Nusselt number is higher in case of $A R=1: 2$ than in case of $A R=2: 1$. In part(3), Nusselt number higher in case of $A R=1: 2$ than in case of $A R=2: 1$.
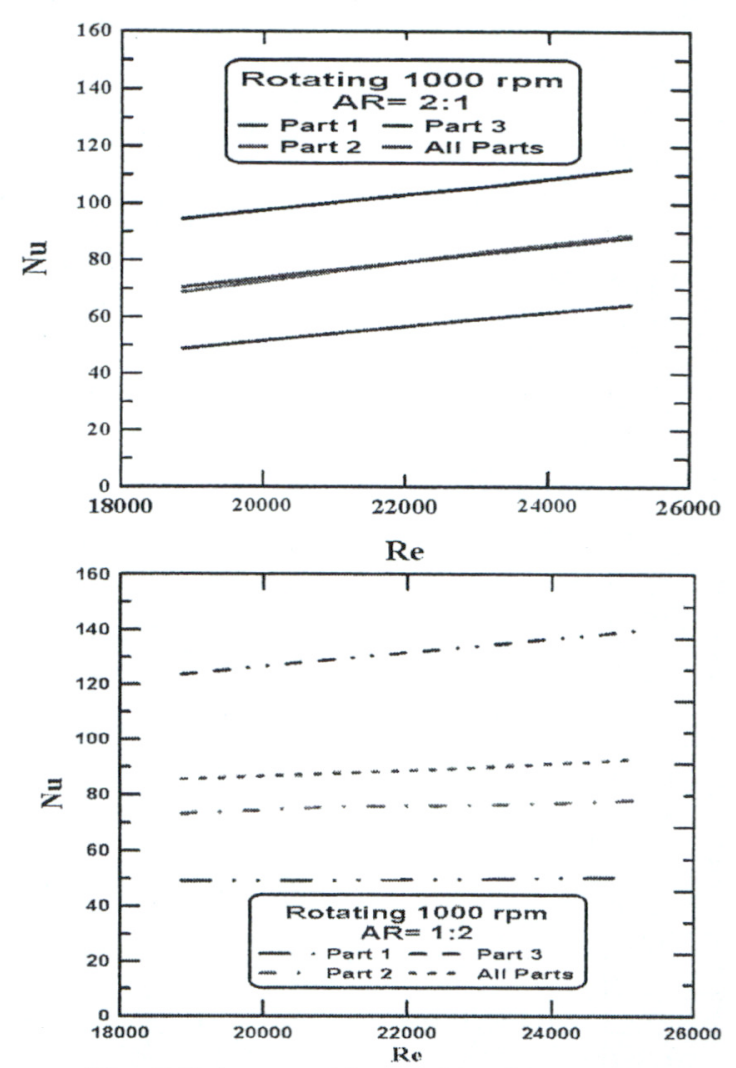

Fig. (11) Average Nusselt Number versus Reynolds Number for two pass Rotating channel.

\subsubsection{Friction factor results}

Figure (12) shows the relation between friction factor $(f)$ and Reynolds number $(\mathrm{Re})$ for whole channel at aspect ratio of 1:2 and 2:1 and rotational speed $(\mathrm{N})$ of 550 
Mansoura Engineering Journal, (MEJ), Vol. 37, No 2, June 2012

$\& 1000 \mathrm{rpm}$. It is shown from the figure that $(f)$ decreases with increases $\mathrm{Re}$, while it decreases (or increases) with $\mathrm{AR}$, and increases or decreases with $(\mathrm{N})$.

\subsubsection{Results of thermal performance}

For the channel average Nusselt number and friction factor ratios, the thermal performance for each channel can be predicted. Figure (13) shows the relation between thermal performance $(\eta)$ and Reynolds number for the whole channel at aspect ratios of $1: 2$ and $2: 1$ and rotational speed $(\mathrm{N})$ of $550 \& 1000 \mathrm{rpm}$.

As shown in Fig.(13), the thermal performance decreases with the increase in the flow Reynolds number.

Considering the performance comparisons of the $A R=2: 1$ and $A R=1: 2$. The highest thermal performance is noticed at $\mathrm{AR}=1: 2$ and $(\mathrm{N})$ at $1000 \mathrm{rpm}$. and the lowest thermal performance at (N) $550 \mathrm{rpm}$.

The highest thermal performance was produced by the $A R=2: 1,(N)$ of $550 \mathrm{rpm}$. and the thermal performance for the $(\mathrm{N})$ of $1000 \mathrm{rpm}$ was the lowest.

\section{Generally:}

The highest thermal performance in rotating case was produced by the $A R=1: 2,(N)$ of $1000 \mathrm{rpm}$.

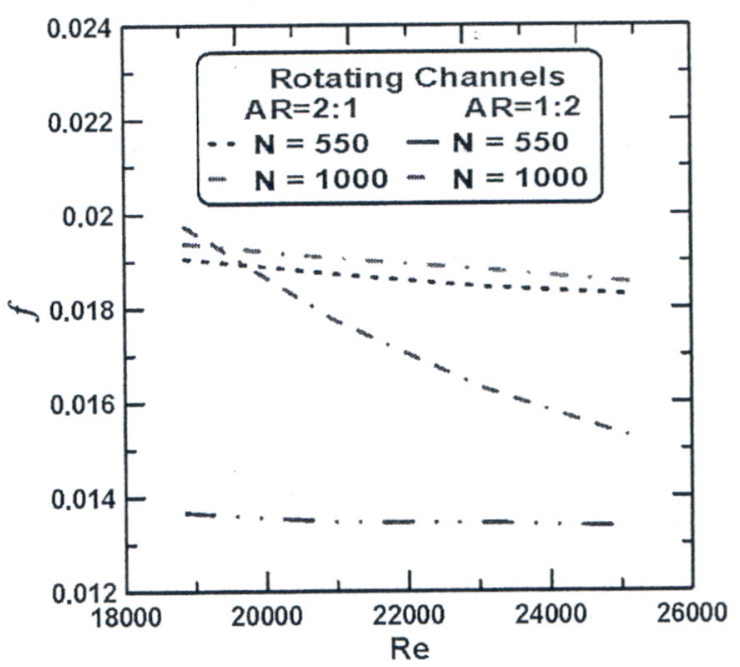

Fig. (12) Friction factor vs. Reynolds number for rotating smooth channel

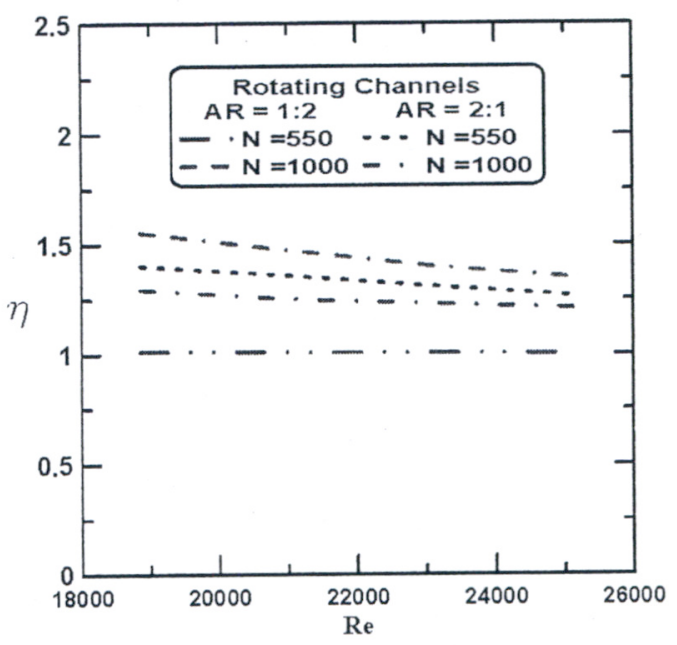

Fig. (13) Thermal Performance vs. Reynolds number for 550 and $1000 \mathrm{rpm}$ rotating channel 
M. 82 Sabry M. Ragab, Ahmed A. Sultan, L. H. Rabee and Moh El-Naggar

\section{Conclusions}

Prediction of heat transfer and flow of rotating and stationary internal cooling channel of gas turbine blades with $\mathrm{AR}=2: 1$ and 1:2. Computations were performed with Reynolds number (Re) ranging from 19,000 to 25,000 , rotation number (Ro) from 0 to 0.1 , inlet coolant-to wall density ratio $(\Delta \rho / \rho)$ of 0.5 , the results show the following:

1- The values of Nusselt number for stationary channels were lower than that of rotating channels for both $(\mathrm{N})$ of $550 \mathrm{rpm}$ and $(\mathrm{N})$ of $1000 \mathrm{rpm}$.

2- The combined effects of the rotational speed, aspect ratio and sharp $180^{\circ}$ turn significantly affect the heat transfer distributions in a two-pass rectangular channel. The secondary flows induced by the sharp $180^{\circ}$ turn play a very prominent role in heat transfer enhancements.

3- The Nusselt number ratio decreases with increasing Reynolds number in both rotating and stationary channels.

4- The highest thermal performance in rotating case is produced for the channel having $A R=1: 2$, at $(N)$ of $1000 \mathrm{rpm}$ and the thermal performance at $(\mathrm{N})$ of $550 \mathrm{rpm}$ is the lowest.

5- The highest thermal performance in rotating case is produced for the channel having $\mathrm{AR}=2: 1$, at $(\mathrm{N})$ of $550 \mathrm{rpm}$. and the thermal performance at $(\mathrm{N})$ of $1000 \mathrm{rpm}$ is the lowest.

\section{References}

1. Han, J. C., Dutta, S. and Ekkad, S. V., 2000, "Gas Turbine Heat Transfer and Cooling Technology", Taylor and Francis, New York.

2. Wen-Lung Fu, "Aspect Ratio Effect On Heat Transfer In Rotating Two-Pass Rectangular Channels With Smooth Walls And Ribbed Walls", Texas A\&M University, May 2005.

3. K.Arun and S. V. Prabhu, "Effect of Aspect Ratio, Channel Orientation, Rib Pitch-to-Height Ratio, and Number of Ribbed Walls on Pressure Drop Characteristics in a Rotating Channel with Detached Ribs" International Journal of Rotating Machinery,2007.

4. Yao-Hsien Liu, "Effect Of Rib Spacing On Heat Transfer And Friction In A Rotating Two-Pass Rectangular ( $\mathrm{AR}=1: 2)$ Channel", Texas A\&M University, August 2005.

5. Luai Al-Hadhrami, Je-Chin Han, "Effect of rotation on heat transfer in two-pass square channels with parallel and crossed 450 angled rib turbulators", Texas A\&M University, Texas 77843-3123.

6. T.M. Liou, S.W. Chang, J.H. Hung, S.F. Chiou, "High rotation number heat transfer of a 45 _ rib-roughened rectangular duct with two channel orientations", International Journal of Heat and Mass Transfer 50 (2007) 4063-4078. 
7. T.-M. Liou, C.C.Chen, "Heat transfer in a rotating two-pass smooth passage with a $180^{\circ}$ rectangular turn), International Journal of Heat and Mass Transfer 42 (1999) 231247.

8. J.C. Han, H.C. "Chen - Annual Report for: AGTSR Project No. SR-094, Rotating Heat Transfer in High Aspect Ratio Rectangular Cooling Passages with Shaped Tabulators",2002.

9. J.C. Han, Phil Ligrani and H.C. ChenAnnual Report for: AGTSR Project No. SR0832, "Rotating and Stationary Rectangular Cooling Passage Heat Transfer and Friction with Ribs, Pins and Dimples", June 2001.

10. Mohammad Al-Qahtani, Yong-Jun Jang, Hamn-Ching Chen and Je-Chin Han, "Flow and heat transfer in rotating two-pass rectangular channels $(\mathrm{AR}=2)$ by Reynolds stress turbulence model", International Journal of Heat and Mass Transfer 45 (2002) 1823-1838.

11. Je-Chin Han and Lesley M. Wright, "Enhanced Internal Cooling of Turbine Blades and Vans", Turbine Heat Transfer Laboratory, Texas A\&M University, 2003.

12. Mohamed Shaye AL-Qahtani, "Computation of Flow and Heat Transfer in Rotating Rectangular Channels With Angled Rib Turbulators For Gas Turbine Blade", Texas A\&M University, August 2001.

13. Maheboob Basha N.B., "Prediction of turbulent heat transfer in a rotating narrow rectangular channel $(A R=10)$ oriented at $120^{\circ}$ from the direction of rotation", King Fahd University of petroleum \& minerals, October 2005.

14. Mohammad Al-Qahtani Yong-Jun JeChin, "Prediction of Flow and Heat Transfer in Rotating Two-Pass Rectangular Channels With45-deg Rib Turbulators", Texas A\&M University, APRIL 2002, Vol. 124 / 1.

15. Hamn-Ching Chen, "Numerical Simulation of Flow and Heat Transfer around Complex Configurations by a Chimera RANS Method", Texas A\&M University, August 2005.

16. Hamn-Ching, Yong-Jun, Je-Chin Han, "Computation of heat transfer in rotating two-pass square channels by a secondmoment closure model", International Journal of Heat and Mass Transfer 43 (2000) 1603-1616.

17. O. Reynolds "The Dynamic Theory of Incompressible Viscous Fluids" http://www.google.com.eg/Books/

18. F. M. White, Fluid Mechanics, 4th ed: McGraw-Hill, 1999.

19. FLUENT CFD code, Version 6.3

20. GAMBIT USER'S GUIDE, Version2.3.16. 